\title{
Attempting to prevent postnatal depression by targeting the mother-infant relationship: a randomised controlled trial
}

Article

Accepted Version

Cooper, P. J., De Pascalis, L., Woolgar, M., Romaniuk, H. and Murray, L. (2015) Attempting to prevent postnatal depression by targeting the mother-infant relationship: a randomised controlled trial. Primary Health Care Research \& Development, 16 (4). pp. 383-397. ISSN 1477-1128 doi:

https://doi.org/10.1017/S1463423614000401 Available at https://centaur.reading.ac.uk/66040/

It is advisable to refer to the publisher's version if you intend to cite from the work. See Guidance on citing.

Published version at: http://journals.cambridge.org/action/displayAbstract?

from $P$ age $=$ online $\&$ aid $=9790123 \&$ fulltextType $=$ RA\&fileld $=S 1463423614000401$

To link to this article DOI: http://dx.doi.org/10.1017/S1463423614000401

Publisher: Cambridge Journals

All outputs in CentAUR are protected by Intellectual Property Rights law, including copyright law. Copyright and IPR is retained by the creators or other copyright holders. Terms and conditions for use of this material are defined in the End User Agreement. 


\section{CentAUR}

Central Archive at the University of Reading

Reading's research outputs online 
Title: Preventing Postnatal Depression by Targeting the Mother Infant Relationship: a randomised controlled trial.

Running title: Preventing postnatal depression.

Authors: Peter J. Cooper ${ }^{1, a}$, Leonardo De Pascalis ${ }^{2}$, Matthew Woolgar ${ }^{2, b}$, Helena Romaniuk ${ }^{2, c}$, Lynne Murray ${ }^{1, a}$

${ }^{1}$ School of Psychology and Clinical Language Sciences, University of Reading, Reading, UK ${ }^{2}$ Research Associate, School of Psychology and Clinical Language Sciences, University of Reading, Reading, UK

${ }^{a}$ Also: Department of Psychology, Stellenbosch University, South Africa.

${ }^{\mathrm{b}}$ Clinical Psychologist, King's College London, National Academy of Parenting Research, London SE5 8AF, UK.

${ }^{\mathrm{c}}$ Biostatistician/Senior Research Officer, Clinical Epidemiology \& Biostatistics Unit and Centre for Adolescent Health, Royal Children's Hospital, Murdoch Children's Research Institute, and Department of Paediatrics, University of Melbourne, Parkville, Victoria 3052, Australia

Correspondence to: Peter J. Cooper or Lynne Murray, School of Psychology and Clinical Language Sciences, University of Reading, Reading, UK, RG6 6AL. Email: p.j.cooper@rdg.ac.uk; lynne.murray@rdg.ac.uk. 


\begin{abstract}
Aim: The purpose of the study was to investigate whether a supportive psychotherapeutic intervention which focussed on enhancing the quality of the other-infant relationship would prevent the development of postnatal depression (PND) and the associated impairments in parenting and adverse effects on child development.
\end{abstract}

Background: Recent meta-analytic examinations report a modest preventive effect of psychological treatments for women vulnerable to the development of postnatal depression. However, given the strong evidence for an impact of PND on the quality of the mother-infant relationship and on child development, it is notable that there are limited data on the impact of preventive interventions on these outcomes. This is clearly a question that requires research attention. Accordingly, a randomized controlled trial was conducted of such a preventive intervention.

Methods: A large sample of pregnant women was screened to identify those at risk of PND. 91 were randomly assigned to the index intervention and received home visits from research health visitors, and 99 were assigned to a control group who received normal care. In an adjacent area 76 women received the index intervention from trained NHS health visitors. The index intervention involved 11 home visits, two antenatally and nine postnatally. They were supportive in nature, with specific measures to enhance maternal sensitivity to infant communicative signals. Independent assessments were made at 18 weeks postpartum, and at 12 and 18 months postpartum of maternal mood, maternal sensitivity in mother-infant engagement, and infant behaviour problems, attachment and cognition.

Findings: The index intervention, whether delivered by research or NHS health visitors, had no discernible impact on maternal mood or the quality of the maternal parenting behaviours. Neither did it benefit the infant outcomes assessed. For girl children a benefit of the intervention was found for cognitive development. Overall the findings indicate that this approach to preventing PND cannot be recommended. 


\section{Introduction}

Depressive disorder arising in the early weeks following childbirth is common, affecting around $13 \%$ of women (O'Hara \& Swain, 1996). These disorders have the same clinical manifestation as depression arising at other times (Cooper, Campbell, Day, Kennerley \& Bond, 1988; O'Hara, 1997). Although most episodes spontaneously remit within four to six months, a significant minority persist beyond a year postpartum (Cooper \& Murray, 1998). There has been considerable concern about the impact of postpartum depression on the mother-child relationship, and on child developmental progress. Child impairments across a wide range of developmental functions have been found (Murray, Halligan \& Cooper, 2010). Thus, the occurrence of depression in the postnatal period has been shown to pose a risk, principally in the context of wider socio-economic difficulties, for poor cognitive functioning in the child, especially boys (e.g. Hay et al., 2001; Murray, Arteche et al, 2010a). Postnatal depression also poses a risk for behaviour problems in later childhood, especially where the postnatal episode becomes chronic (e.g. Ghodsian, Zajicek, \& Wolkind, 1984; Sinclair \& Murray, 1998; Morrell $\&$ Murray, 2003). Finally, there is evidence for effects of postnatal depression on HPA axis functioning in offspring (Halligan, Herbert, Goodyer \& Murray, 2004), which is itself a risk for depression; and, indeed, there is accumulating evidence for the effect of postnatal depression on the risk for depression in adolescent offspring, again, especially where the maternal postnatal depression becomes chronic (Hammen \& Brennan, 2003; Hay et al, 2008; Murray et al., 2011). Notably, the adverse impact of postnatal depression on these child outcomes has been found to be mediated by specific impairments in the mother-infant relationship (Murray, Halligan \& Cooper, 2010). This includes difficulties such as a lack of contingent, infant-focused responsiveness (Murray, Kempton, Woolgar \& Hooper, 1993), hostile and intrusive interactions (Morrell \& Murray, 1993), withdrawn and disengaged behaviour (Murray, Halligan \& Cooper,, 2010), and vocally communicated sad affect (Murray, Marwick, \& Arteche, 2010).

In light of these concerns about the impact of postnatal depression on child development, the question has been raised whether postpartum depression should be clinically targeted specifically to improve child developmental progress and mental health (McLennan \& Offord, 2002). There are arguments both in favour and against such a notion. In favour is the fact that screening for postpartum depression can be effected reliably and economically 
(Cox, Holden \& Sagovsky, 1987; Murray \& Carothers, 1990; Morrell et al, 2009a), the relatively high prevalence of postpartum depression (O'Hara, 1997), the reliability of the association between postpartum depression and adverse outcomes (Murray et al., 2010b), and the fact that several studies have demonstrated that therapeutic intervention is effective in alleviating maternal depression (e.g. Holden, Sagovsky \& Cox, 1989; Wickberg \& Hwang, 1996; Appleby, Warner, Whitton \& Faragher, 1997; O’Hara, Stuart, Gorman \& Wenzley, 2000; Cooper, Murray, Wilson \& Romaniuk, 2003; Morrell et al, 2009). Against the idea of targeting maternal depression to improve child outcome is the fact that there is very little evidence that successful treatment of postpartum depression is of benefit to the mother-child relationship and the developing child (Foreman et al, 2007; Nylen, Moran, Franklin \& O'Hara, 2007). Indeed, only three of the controlled trials on treatment have addressed these issues (Murray, Cooper, Wilson \& Romaniuk, 2003; Forman et al, 2007; Morrell et al, 2009b). In the former, UK study, although there was some benefit of treatment in terms of child behavioural disturbance and the mother-child relationship, this only emerged on measures that relied on maternal self-report (Murray et al., 2003). Similarly, in the US study, only parenting stress, and not the mother-child relationship or child outcome itself showed a benefit (Forman et al, 2007). In the most recent study (Morrell et al, 2009), although some benefit of the intervention at 18 months postpartum was apparent in terms of infant behavior problems, the effect was not strong, and, again, this relied entirely on maternal self-report. Before recommending targeting maternal depression in order to improve child outcome, it would be necessary to demonstrate more convincingly than has been the case to date that improvement in maternal mood is of material benefit to child developmental progress.

In the absence of such evidence, a further approach to this issue is to attempt to prevent the maternal depression itself. There have been several studies conducted with this specific objective. The results of 15 of these were summarised in a systematic review in 2005 (Dennis, 2005). At that time the conclusion drawn was that there was insufficient evidence to recommend the introduction of preventive interventions; however, the authors noted that interventions most likely to be beneficial were those that targeted high risk women, and that were delivered individually and largely postnatally. Recently (Dennis \& Dowswell, 2013), this review has been updated, now covering 28 trials reported between 1995 and 2011 , involving almost 17,000 women. The conclusions drawn were considerably more positive than they had been in 2005.Thus, when considering depression at the last point of 
assessment, pooling all forms of intervention, a beneficial effect was reported on the prevention of depressive symptomatology (20 trials, $n=14,727)$. A significant preventive effect was also found among the few studies that included a clinical diagnosis of depression (five trials; $\mathrm{N}=939)$. Further analyses revealed an immediate $(13$ trials; $\mathrm{N}=4,907)$ and short-term (10 trials; $\mathrm{N}=3982$ ) impact of the preventive interventions on depressive symptomatology. This preventive effect appeared to weaken at the intermediate postpartum time period between 17 to 24 weeks (nine trials; $\mathrm{N}=10,636$ ), but was again significant when depressive symptomatology was assessed beyond 24 weeks postpartum (five trials; $\mathrm{N}$ =2936). Among trials that included a clinical diagnosis of depression, no preventive effect across an extended postpartum period was found, but there was a short-term beneficial effect (four trials; $\mathrm{N}=902$ ). Data on the impact on child development are scarce, and on the quality of the mother-infant relationship, largely absent. Thus, from one trial that dichotomised maternal-infant attachment as secure or insecure, and two that examined mean scores on a maternal-infant measure (Armstrong et al., 1999, Feinberg \& Kan, 2008), Dennis \& Dowswell (2013) conclude that there is no significant effect of the preventive intervention (two trials; $\mathrm{N}=268$ ) ; and from the one trial that reported on infant cognitive development (Cupples et al, 2011) they also report no benefit $(\mathrm{N}=280)$.

Thus, while there is evidence for a positive benefit of preventive interventions on maternal mood, especially in the short term, it is notable that only one study to date (Armstrong et al., 1999) has made a direct examination of whether a preventive intervention has any impact on the quality of the mother child relationship, and few studies have considered the impact of intervention on any dimensions of child developmental outcome. This is clearly a question that requires research attention.

The preventive interventions examined to date have typically involved nurses or midwives providing general support (although there is also evidence for the benefit of more specific interventions, such as interpersonal psychotherapy). However, women who develop depression following delivery commonly report difficulties in their relationship with their infant and in managing infant behaviour problems (Murray 1992; Seeley, Murray \& Cooper 1996). It might be expected that specific help in these domains would benefit vulnerable women in the early postpartum period. In view of these considerations, and consistent with the recommendations of Dennis and colleagues (2005; 2013), a trial was conducted of an individually delivered home-based preventive intervention provided by a health care 
professional, with the therapeutic input concentrated on the early weeks following delivery, and the intervention designed to provide the mother with specific help in managing the care of her infant, as well as general emotional support.

\section{Method}

The study was conducted in Reading, Berkshire. In one area, corresponding to the southern half of the city (Reading South), an efficacy, randomized controlled trial (RCT) study was conducted; that is, appropriate women were identified (see Sampling below) and assigned by simple randomisation, using consecutively numbered, opaque, sealed envelopes, to either routine primary care, or to an index preventive condition (R-HV) delivered by research Health Visitors (see Intervention and therapists below). In the northern sector (Reading North) there was no randomisation. Instead, all appropriate women were identified and treated by their local NHS health visitor (NHS-HV) who had been trained to deliver the intervention (see Intervention and therapists below). Assessments were made at eight and 18 weeks postpartum, and at 12 and 18 months postpartum.

The authors assert that all procedures contributing to this work comply with the ethical standards of the local NHS Research Ethics Board and the University of Reading Research Ethics Board.

\section{Sampling}

Primiparous women attending the 20 week scan at the Royal Berkshire Hospital were screened for risk for postpartum depression using a predictive index (Cooper, Murray, Hooper \& West, 1996). Women who scored highly on the questionnaire (i.e. a score of more than 15 which represents a 30\% risk of postnatal depression (Cooper et al, 1996)), and met the study inclusion criteria (e.g., single pregnancy, stable residence in the area, English the home language) were identified as potential participants for the study. Sample size was calculated on the basis of a significant reduction in the prevalence of major depression at 8 weeks, based on SCID criteria. All those agreeing to participate who were resident in Reading South were randomly assigned to either the Index (R-HV) or the control condition. Those women who were resident in Reading North were all allocated to the Index (NHS-HV) arm of the study. During the initial recruitment phase of the study, women were contacted either by telephone or letter to arrange a recruitment visit. All women assigned to 
the Index (R-HV) or the Index (NHS-HV) who gave their consent during recruitment were offered their assigned treatment. Those who completed treatment and the women from the control group were then assessed at eight and 18 weeks postpartum, and at 12 and 18 months postpartum.

\section{Intervention and therapists}

The intervention comprised three principal elements. First, supportive counselling was provided (as in Holden et al, 1989). The object was to encourage the women to express their feelings in a non-judgemental and supportive context. Second, specific strategies were employed to sensitise the mothers to their infants' characteristics. In particular, selected items from the Brazelton Neonatal Behavioral Assessment Scale, or NBAS (Brazelton \& Nugent, 1995) were used to form an Interactive Neonatal Assessment (manual available on request). These focused on infant responsiveness to the social and non-social environment (e.g. visual tracking, responding to the mother's voice), as well as individual differences in infant capacities for regulating their state and behavioural responses (e.g., via habituation, and covering the infant's eyes briefly with a soft cloth). Finally, specific help was provided to the mothers in managing infant behavioural problems (i.e. sleeping, feeding, crying - as outlined in The Social Baby (Murray and Andrews, 2000)). The therapists were all NHS employed Health Visitors. For the Index (R-HV) arm, two Health Visitors were seconded to work within the research team, and were provided with training. Specifically, they received formal training in the administration of the NBAS; and they delivered pilot interventions to a sample of high risk mothers, under the supervision PJC and LM. For the Index (NHS-HV arm), training was provided to all the NHS employed Health Visitors working in the Reading North sector. The intervention involved 11 home visits: two antenatally and then nine in the first 16 weeks postnatally.

\section{Assessments}

Post-intervention assessments were made, blind to treatment condition, at eight and 18 weeks postpartum, and at 12 and 18 months postpartum. The first two of these were conducted in the women's own homes, and the latter two in the research base. At all four time points assessment was made of maternal mood using the Structured Clinical Interview for DSM-IV diagnoses (SCID) (First, Spitzer, Gibbon \& Williams, 1997), and the 
Edinburgh Postnatal Depression Scale (EPDS) (Cox, Holden \& Sagovsky, 1987). At the eight and 18 week postpartum assessment, a video recording was made of the mother and her infant engaged in a face to face interaction (Murray, Fiori-Cowley, Hooper \& Cooper, 1996). In addition, at the first three assessments mothers completed a self-report questionnaire on relationship problems with the infant, and infant behaviour problems (Murray et al, 2003); and at the 18 month postpartum assessment, mothers completed the Behaviour Screening Questionnaire (Richman and Graham, 1971), modified for this age group (Murray, 1992), to assess child behavior problems . At 18 months, assessment was made of infant mental development, using the Bayley II Scales for Infant Development Mental Development Index (MDI) (Bayley, 1993), and the Ainsworth Strange Situation Procedure was used to assess infant security of attachment (Ainsworth, Blehar, Waters \& Wall, 1978). Both are 'gold standard', reliable, measures that are widely used in infancy research and have been shown to be sensitive to effects of maternal postnatal depression (Murray et al, 1996). In the case of the Bayley scales, there have been reports that infant gender moderates this relationship, with boys being more adversely affected, whereas girls appear to have good cognitive outcome (Murray, Arteche et al, 2010) In the current study, therefore, we examined the moderating effect of child gender on the relationship between intervention and performance on the Bayley II MDI. The mental state assessments and coding of attachment videos were conducted by trained independent assessors/coders who were masked with respect to treatment condition.

\section{Data Analysis}

Summary statistics were calculated for the demographic characteristics, predictive index components, and outcome measures by treatment group. A multilevel modelling framework was used to estimate the effect of the Index (R-HV) condition compared to the control group for outcomes measured over time. Linear models were used for continuous measures - i.e. EPDS, maternal sensitivity, and infant engagement. Logistic regression was used for binary outcome measures - i.e. SCID diagnoses of depression, and the presence of marked to moderate behavioural and relationship problems. For each measure, a first set of models assessed the effect of treatment, and its interaction with time of assessment, while a second set of models assessed the effect of treatment, and its interaction with the predictive index score. For the outcomes only measured at 18 months, linear regression was used to analyse the BSQ scores and the Bayley Mental Development scores, while logistic regression was 
used to model infant attachment. These models initially assessed the effect of treatment, and subsequently also included its interaction with the predictive index score. Only for the Bayley Mental Development score, a final model assessed the interaction between treatment and child gender. To compare the Index (NHS-HV) and control conditions, the same set of analyses was conducted. All analyses were performed using SPSS version 22, for Microsoft Windows. A p-value $<0.05$ was considered significant, with a Bonferroni correction for multiple comparisons.

\section{Results}

As can be seen from the CONSORT diagram (see Figure 1), $87 \%$ of the 2592 women selected for screening completed the questionnaire. Six hundred and forty five women (29\% of the women who completed the questionnaire) scored above the cut off on the predictive index. One hundred and sixty-six of these women were randomly assigned to a separate ongoing study of parenthood, and they are not considered further. Of the remaining women, 76 were ineligible to participate (e.g., twin pregnancy, moving away from area), leaving 403 who were identified as potential recruits for the study. One hundred and thirteen of the 150 randomly assigned to the Index (R-HV) (75\%) agreed to a recruitment visit, as did 78 of the 102 assigned to the Index (NHS-HV) (76\%) and 107 of the 151 assigned to the control group (71\%). During the recruitment visit, $61 \%$ of the women randomly allocated to the Index (R-HV) condition consented to participate in the study, as did 75\% of the Index (NHS-RV) and $66 \%$ of the controls. Of the women who consented to participate in the study, $90 \%$ of the Index(R-HV) women and 79\% of the Index (NHS-HV) women completed treatment; and $88 \%$ of the controls were retained in the study over the equivalent period of time. At the eight week postpartum assessment, all the women who completed treatment in the Index (R-HV) condition were assessed, as were all but two of the women in the Index (NHS-HV) group and all but four of the controls. At the 18 month assessment, $90 \%$ of the Index(R-HV) women who had completed treatment were assessed, as were 85\% of the Index (NHS-HV) and 85\% of the controls. 
Table 1 provides details of the three groups, in terms of the mother's age, child's gender, and their responses to the individual items of the predictive index. It is apparent that there were no material differences between the three groups at base-line. The analyses below are presented in terms of overall comparative statistics. (Details of exact scores and distribution on all measures are available on request).

\section{Table 1 about here}

\section{Maternal Mood}

\section{EPDS}

The distribution of scores on the Edinburgh Postnatal Depression Scale was positively skewed, and the variable was square-root transformed prior to analysis to achieve normality. From Table 2, it can be seen that at each assessment, the mean EPDS scores were similar for each of the three groups. No main effect of group (all $p s>.857$ ), or interaction with time (all $p s>.235)$ was found for either the Index (R-HV) vs. Control, or the Index (NHS-HV) vs. Control comparisons. EPDS scores were, however, significantly predicted by the total risk index score $(\mathrm{F}(1,228.14)=10.75 ; p=.001)$. For both Index (R-HV) and Index (NHS-HV), however, the risk score did not moderate the relationship between intervention and EPDS (both $p \mathrm{~s}>.098$ ).

\section{SCID}

The proportion of women who were depressed at each assessment is shown in Table 2 for each of the three groups. Compared to the control condition, for both Index (R-HV) and Index (NHS-HV), at none of the assessments was there a main effect of group (all $p \mathrm{~s}>.687$ ), nor was there an interaction with time (all $p s>.597$ ). The total risk index score predicted the overall likelihood of being depressed $(\mathrm{F}(1,836)=17.22 ; p<.001)$; however, for both Index (R-HV) and Index (NHS-HV), the risk score did not moderate the relationship between intervention and SCID status (all $p s>.079$ ).

Table 2 about here 


\section{Mother-Infant Interactions}

\section{Maternal Sensitivity}

As can be seen from Table 3, in terms of the levels of maternal sensitivity, compared to the control condition, for both Index (R-HV) and Index (NHS-HV), there was no main effect of group at either 8 or 18 weeks (all $p \mathrm{~s}>.365$ ), nor was there an interaction with time (all $p \mathrm{~s}>.759$ ). Maternal sensitivity was not predicted by the total risk index score ( $p=.638)$; and for both Index (R-HV) and Index (NHS-HV), the risk score did not moderate the relationship between intervention and maternal sensitivity (all $p \mathrm{~s}>.109$ ).

\section{Infant Interaction}

As can be seen from Table 3 which concerns levels of infant engagement, compared to the control condition, there was no effect of group for either Index (R-HV) or Index (NHS-HV) at either 8 or 18 weeks (all $p s>.233$ ), and nor was there an interaction with time (all $p s>.231$ ). No relationship was found between infant engagement and the total risk index score ( $p=.123)$; and for neither Index (R-HV) nor Index (NHS-HV), did the risk score moderate the relationship between intervention and infant engagement (all $p \mathrm{~s}>.215$ ).

\section{Table 3 about here}

\section{Reported Behaviour and Relationship Problems}

For reported behavioural problems at 8 and 18 weeks, and at 12 months, as shown in Table 4, comparing the women in the Index(R-HV) and the control condition, there was no main effect of group at any time point (all $p s>.570$ ), nor an interaction with time (all $p s>.229$ ). For the comparison between the Index (NHS-HV) group and the control group, there was a main effect of group $(\mathrm{F}(1,382)=9.440 ; p=.002)$, with women in the former being less likely to report behaviour problems, regardless of time. No interaction between time and group was found $(p=.882)$. The total risk index score did not predict reported behavioural problems; and for neither Index(R-HV) nor Index(NHS-HV) did the risk score moderate the relationship between intervention and the presence of behavior problems (all $p s>.454$ ). 
In relation to reported relationship problems, also measured at 8 and 18 weeks and 12 months, as shown in Table 4, there was no main effect of group for the comparison between the control and the Index(R-HV) conditions ( $p=.131)$, or between the control and the Index(NHS-HV) conditions $(\mathrm{F}(1,360)=3.404 ; p=.066)$. Neither comparison showed an interaction between group and time (all $p s>.722$ ). The total risk index score did not predict reported relationship problems in the sample as a whole $(p=.202)$, and, for the comparison between Index(NHS-HV) and controls, no moderating effect of risk score on the relationship between intervention and relationship problems was found ( $p=.523)$. In the comparison between Index(R-HV) and controls, however, the risk score was found to moderate the relationship between intervention and reported relationship problems $(p=.002)$ : for mothers in the index group, those with a higher risk score were more likely to report relationship problems than those with lower initial risk, whereas for controls, relationship problems were independent of initial risk score.

The distribution of scores on the Behaviour Screening Questionnaire, collected at 18 months, was positively skewed. The variable was therefore square-root transformed. The BSQ scores, shown in Table 4, did not differ significantly between either of the index conditions and the control condition (all $p s>$.692). No relationship was found between BSQ scores and the total risk index score ( $\mathrm{p}=.065)$; and, for both Index (NHS-HV) and Index (R-HV), the risk score did not moderate the relationship between intervention and BSQ, (all $p \mathrm{~s}>.157$ ).

\section{Table 4 about here}

\section{Bayley Scales of Mental Development (MDI)}

For the Bayley MDI score, at 18 months, neither the Index (R-HV) vs. Control nor Index (NHS-HV) vs. Control comparisons showed a main effect of group (both $p s>.765$ ). Total risk index scores were negatively associated with Bayley MDI scores ( $p=.023)$, with higher risk index scores being associated with lower Bayley MDI scores. For neither Index (NHS-HV) nor Index (R-HV), did the risk score moderate the relationship between intervention and Bayley MDI score (all $p s>.267$ ). When gender was considered as a possible moderator of the relationship between intervention and Bayley MDI score, one significant finding emerged ( $p=0.020)$ : the girls in the Index(R-HV) group had a 13.85 MDI advantage over the boys from the same group ( $p<0.001$ Bonferroni corrected), and an 8.20 IQ advantage over the girls from 
the control group ( $p=0.056$ Bonferroni corrected). For the Index (NHS-HV) groups, the girls had an IQ advantage over the boys of 7.04 points, although this does not represent significant moderation ( $p=0.178$ Bonferroni corrected). Amongst controls, gender was unrelated to Bayley MDI score (M’s = 94.52 and 95.46 for boys and girls, respectively; $p=0.829$ Bonferroni corrected).

\section{Infant Attachment Security}

At 18 months, no difference was found in the proportion of securely attached infants of control group mothers $(66.67 \%)$ compared to infants of Index (R-HV) mothers $(65.71 \%)$ and infants of Index (NHS-HV) mothers $(50.98 \%)\left(\chi^{2}(1)=0.01\right.$ and $\chi^{2}(1)=3.06$, respectively; $\left.p s>.080\right)$. The total risk index score did not predict infant attachment $(p=.809)$; and for neither Index(NHS-HV nor Index(R-HV), did the risk score moderate the relationship between intervention and infant attachment (both $p \mathrm{~s}>.592$ ).

\section{Perceptions of the Intervention}

A set of questions was drawn up to ascertain participants' perceptions of the intervention (see Table 5). To enable comparison with the control group, these were formulated as assessments of the extent, and way in which they found the home visiting helpful, with scores ranging between 0 (Not at all) and 3 (Completely). Table 5shows items and mean scores for this questionnaire. It is apparent those in the two index intervention groups felt better supported than the controls, both emotionally and practically (all $p s<0.004$ ); and they also felt their relationship with their infant had been better facilitated (all $p s<0.001$ ).

\section{Table 5 about here}

\section{Discussion}

A recent systematic review of the controlled trials examining the impact of preventive interventions for postnatal depression reported a positive benefit (Dennis \& Dowswell, 2013). This effect has mainly been shown on depressive symptoms in the early weeks following delivery. No impact on the quality of the mother-infant relationship or child development has been shown, but only a handful of studies have included child variables as outcomes. This is a 
significant gap in the literature. There is considerable evidence of both a strong association between postpartum depression and impairments in the mother-child relationship (Murray et al, 1996), and between such impairments and adverse child outcomes (Murray, Halligan \& Cooper, 2010). The current trial attempted to address this gap by delivering a preventive intervention that, in the context of providing general emotional and practical support, directly addressed the mother-infant relationship. This intervention was delivered by trained health visitors to women at established raised risk for postpartum depression. Maternal mood was assessed and direct assessment was made of both the quality of the mother infant relationship and critical dimensions of child development progress. Assessment of efficacy was made in a standard RCT; and an attempt to assess effectiveness was made by including a trial arm where the therapists were NHS health visitors.

The strengths of the trial were the rigorous manner in which the high risk samples were identified, the systematic assessment of maternal mood, the mother-child relationship and child outcome, and the provision of a specifically targeted intervention. A limitation was that there were no strong empirical grounds for believing that a mother-child intervention of the sort delivered would be of benefit to maternal mood, although it was reasonable to expect benefit for child outcome.

No impact of the intervention was found on maternal depression, either in terms of level of symptoms or a diagnosis of depressive disorder at any of the assessment points. This absence of therapeutic benefit was not a function of unexpected low levels of depression in the control sample. Indeed, the period prevalence of depressive disorder at 8 weeks postpartum for the intervention and the control groups was very much in line with the rate the predictive index would have predicted, in the absence of an intervention (Cooper et al, 1996). The unavoidable conclusion must be that, in terms of depressive mood and disorder, this intervention was not of benefit to the women. This was a surprising finding because a core component of the intervention was supportive counselling. This therapeutic approach has, in some previous studies (though not others), been found to have a preventive effect (Dennis \& Dowswell, 2013).

A notable feature of the current study was the fact that direct assessment of the quality of the mother-infant relationship was made. No benefit of the intervention for the mother-child relationship was found. Thus, no treatment effect was apparent for the level of maternal 
sensitivity in interaction with the infant, or the levels of infant engagement. These null findings were largely replicated in the maternal self-report measures of infant behaviour and relationship problems. Again, this was an unexpected finding. Interventions of the sort being delivered, which focus on the mother-child relationship and infant problems have, in other contexts, been shown to be of benefit (e.g. Cooper et al, 2009). It is of interest that these negative findings, based on objective measures of the mother-child relationship, are in contrast to the views of participants themselves: the mothers reported the intervention to be of considerable emotional and practical support, and to be of significant help in enhancing the quality of their relationship with their baby. This must cast into doubt the validity of using maternal reports of the benefit of mother-infant interventions in intervention studies.

Scant attention has been paid in previous preventive studies of the impact of treatment on child outcomes, such as attachment and cognition. Both of these outcomes were carefully assessed in the current trial using rigorous methods of assessment. No impact of the intervention was found for either security of infant attachment or cognitive development. These are unsurprising findings, given the lack of effect on both maternal depression and the quality of the mother-child relationship.

It does not seem likely that the reason for our null findings is that the predictive index we used to identify participants failed to function as intended. First, the proportion of women in the control condition who experienced depression in the weeks following childbirth was in line with expectations. Second, overall antenatal risk was found to be a reliable predictor of several key outcomes, including maternal depressive mood and disorder, maternal sensitivity in interaction with the infant, and the 18 month infant Bayley MDI score. Importantly, however, the level of risk did not moderate the impact of the intervention on outcome (apart from in one comparison concerning maternal reports of relationship problems). One unexpected moderation effect did emerge: in terms of child Bayley MDI score, there appeared to be a reliable benefit of the intervention for girl children. In light of the plethora of other negative findings, this effect must be regarded with considerable caution.

The thrust of the recent systematic review of preventive interventions for postnatal depression (Dennis \& Dowswell, 2013) is that some forms of intervention do appear to be of benefit to maternal mood, especially in the short term. This is an important advance as, until recently, the research appeared to be pointing to the absence of a preventive effect (Dennis, 2005). Thus, 
positive evidence has emerged for intensive, individualised postpartum home visits provided by public health nurses or midwives, lay (peer)-based telephone support, and interpersonal psychotherapy (Dennis \& Dowswell, 2013). Whether these forms of intervention are also of positive benefit to the mother-child relationship and child developmental progress remains to be demonstrated. What the findings of the current study suggest is that a preventive intervention, delivered by health visitors to a high risk UK sample, which focuses on the mother-infant relationship, is likely to be ineffective, both at preventing the maternal mood disorder and the associated mother-infant relationship disturbances.

It is of some interest to note that in a context very different from the UK one in which this trial was conducted, the delivery of the current intervention produced very different findings (Cooper et al, 2009). Thus, when the intervention (with some culturally appropriate modifications) was delivered to a group of impoverished South African mothers, while only a modest positive benefit on maternal mood was found, the intervention was of significant benefit to both the quality of the mother-child-relationship and infant security of attachment. Why there should be such a contrast between these two contexts is moot. Two possible explanatory candidates are worth considering. First, in the UK study the intervention visits stopped at two months postpartum, whereas in the South African study they continued until six months. The extra support provided could have been a key difference. A second possible explanation concerns sample engagement with the content of the intervention. The South African women were extremely keen to engage in the intervention because they believed that it would be benefit to their children. Motivating the UK sample was much more problematic.

Given that the findings of the current study are somewhat out of step with the conclusions drawn from other recent preventive intervention studies, we are wary of making strong recommendations on the direction for future research. However, it is clear that even where preventive effects have been found, they are modest compared to the impressive results obtained from treating identified depression. In light of this, clinical practice may well benefit more from refinement of identification and treatment procedures than further elaborating preventive ones. Further, for both preventive and treatment studies, a reliable impact on the mother-child relationship and child outcome remains to be demonstrated. This must represent a major focus for future research. 


\section{Acknowledgements}

We thank Shirley Goldin and Angela Cameron for assistance in supervision of Health Visitor practice, Joanna Hawthorne for training the Health Visitors in the administration of the NBAS, the Health Visitors who acted as therapists, and the mothers who participated in the study. We also thank Liz McGregor for assistance with recruitment, and Liz Schofield and Claire Lawson for help with conducting assessments and coding.

\section{Financial Support}

The study was funded by the National R and D programme MCH-1-44.

\section{Conflicts of Interest:}

The authors have no conflicts of interests to declare. 


\section{References}

Ainsworth M, Blehar M, Waters E, Wall S. Patterns of attachment. (1978) Hillsdale, NJ: Erlbaum.

Appleby, L., Warner, R., Whitton, A., \& Faragher, B. (1997). A controlled study of fluoxetine and cognitive-behavioural counselling in the treatment of postnatal depression. $B M J$, $314,932-936$.

Armstrong, K. L., Fraser, J. A., Dadds, M. R., \& Morris, J. (1999). A randomized, controlled trial of nurse home visiting to vulnerable families with newborns. Journal of Paediatrics and Child Health, 35(3), 237-244.

Bayley N. Bayley Scales of Infant Development. 2nd ed. San Antonio, TX: Psychological Corp; 1993

Brazelton, T. B. \& Nugent, J. K. (1995). The Neonatal Behavioural Assessment Scale. (3rd ed.) London: MacKeith Press.

Cooper, P. J., \& Murray, L. (1998). Postnatal depression. BMJ, 316, 1884-1886.

Cooper, P. J., Campbell, E. A., Day, A., Kennerley, H., \& Bond, A. (1988). Non-psychotic psychiatric disorder after childbirth. A prospective study of prevalence, incidence, course and nature. The British Journal of Psychiatry, 152(6), 799-806.

Cooper, P. J., Murray, L., Hooper, R., \& West, A. (1996). The development and validation of a predictive index for postpartum depression. Psychological Medicine, 26(3), 627-634.

Cooper, P. J., Murray, L., Wilson, A., \& Romaniuk, H. (2003). Controlled trial of the short-and long-term effect of psychological treatment of post-partum depression 1. Impact on maternal mood. The British Journal of Psychiatry, 182(5), 412-419.

Cooper, P. J., Tomlinson, M., Swartz, L., Landman, M., Molteno, C., Stein, A.\&Murray, L. (2009). Improving quality of mother-infant relationship and infant attachment in socioeconomically deprived community in South Africa: randomised controlled trial. BMJ, 338, b974.

Cox, J. L., Holden, J. M., \& Sagovsky, R. (1987). Detection of postnatal depression. Development of the 10-item Edinburgh Postnatal Depression Scale. The British Journal of Psychiatry, 150(6), 782-786. 
Cupples, M. E., Stewart, M. C., Percy, A., Hepper, P., Murphy, C., \& Halliday, H. L. (2011). A RCT of peer-mentoring for first-time mothers in socially disadvantaged areas (The MOMENTS Study). Archives of Disease in Childhood, 96(3), 252-258.

Dennis, C. L. (2005). Psychosocial and psychological interventions for prevention of postnatal depression: systematic review. $B M J, 331,15-22$.

Dennis, C. L., \&Dowswell, T. (2013). Psychosocial and psychological interventions for preventing postpartum depression - The Cochrane Collaboration. Wiley.

Feinberg, M. E., \& Kan, M. L. (2008). Establishing family foundations: intervention effects on coparenting, parent/infant well-being, and parent-child relations. Journal of Family Psychology, 22(2), 253-263.

First, M. B., Spitzer, R. L., Gibbon M., \& Williams, J. B. W. (1996). Structured Clinical Interview for DSM-IV Axis I Disorders, Clinician Version (SCID-CV). Washington, D.C.: American Psychiatric Press.

Forman, D. R., O'Hara, M. W., Stuart, S., Gorman, L. L., Larsen, K. E., \& Coy, K. C. (2007). Effective treatment for postpartum depression is not sufficient to improve the developing mother-child relationship. Development and Psychopathology, 19(02), 585-602.

Ghodsian, M., Zajicek, E., \& Wolkind, S. (1984). A longitudinal study of maternal depression and child behaviour problems. Journal of Child Psychology and Psychiatry, 25(1), 91-109.

Halligan, S. L., Herbert, J., Goodyer, I. M., \& Murray, L. (2004). Exposure to postnatal depression predicts elevated cortisol in adolescent offspring. Biological Psychiatry, 55(4), 376-381.

Hammen, C., \& Brennan, P. A. (2003). Severity, chronicity, and timing of maternal depression and risk for adolescent offspring diagnoses in a community sample. Archives of General Psychiatry, 60(3), 253-258.

Holden, J.M., Sagovsky, R. and Cox, J. (1989) Counselling in a general practice setting: controlled study of health visitor intervention in treatment of postnatal depression. British Medical Journal, 298: 223-226.

Hay, D. F., Pawlby, S., Sharp, D., Asten, P., Mills, A., \& Kumar, R. (2001). Intellectual problems shown by 11-year-old children whose mothers had postnatal depression. Journal of Child Psychology and Psychiatry, 42(7), 871-889. 
Hay, D. F., Pawlby, S., Waters, C. S., \& Sharp, D. (2008). Antepartum and postpartum exposure to maternal depression: different effects on different adolescent outcomes. Journal of Child Psychology and Psychiatry, 49(10), 1079-1088.

Holden, J. M., Sagovsky, R., \& Cox, J. L. (1989). Counselling in a general practice setting: controlled study of health visitor intervention in treatment of postnatal depression. BMJ, 298, 223-226.

McLennan, J. D., \& Offord, D. R. (2002). Should postpartum depression be targeted to improve child mental health? Journal of the American Academy of Child \& Adolescent Psychiatry, 41(1), 28-35.

Morrell, C. J., Slade, P., Warner, R., Paley, G., Dixon, S., Walters, S. J., Nicholl, J. (2009). Clinical effectiveness of health visitor training in psychologically informed approaches for depression in postnatal women: pragmatic cluster randomised trial in primary care. BMJ, 338, a3045.

Morrell, C. J, Warner, R., Slade, P., Dixon, S., Walters, S., Paley, G. and Brugh, TR (2009) Psychological interventions for postnatal depression: cluster randomised trial and economic evaluation. The PoNDER trial. Health Technology Assessment 2009; Vol. 13: No. 30

Morrell, J., \& Murray, L. (2003). Parenting and the development of conduct disorder and hyperactive symptoms in childhood: A prospective longitudinal study from 2 months to 8 years. Journal of Child Psychology and Psychiatry, 44(4), 489-508.

Murray, L. (1992). The impact of postnatal depression on infant development. Journal of Child Psychology and Psychiatry, 33(3), 543-561.

Murray, L. and Andrews, L. (2000) The Social Baby. Constable\&Robinson. London.

Murray, L., \& Carothers, A. D. (1990). The validation of the Edinburgh Post-natal Depression Scale on a community sample. The British Journal of Psychiatry, 157(2), 288-290.

Murray, L., Arteche, A., Fearon, P., Halligan, S., Croudace, T., \& Cooper, P. (2010). The effects of maternal postnatal depression and child sex on academic performance at age 16 years: a developmental approach. Journal of Child Psychology and Psychiatry, 51(10), 1150-1159.

Murray, L., Arteche, A., Fearon, P., Halligan, S., Goodyer, I., \& Cooper, P. (2011). Maternal postnatal depression and the development of depression in offspring up to 16 years of age. Journal of the American Academy of Child \& Adolescent Psychiatry, 50(5), 460-470. 
Murray, L., Cooper, P. J., Wilson, A., \& Romaniuk, H. (2003). Controlled trial of the short-and long-term effect of psychological treatment of post-partum depression 2. Impact on the mother-child relationship and child outcome. The British Journal of Psychiatry, 182(5), 420-427.

Murray, L., Fiori-Cowley, A., Hooper, R., \& Cooper, P. (1996). The impact of postnat aldepression and associated adversity on early mother-infant interactions and later infant outcome. Child Development, 67(5), 2512-2526.

Murray, L., Halligan, S., \& Cooper, P. (2010). Effects of postnatal depression on mother-infant interactions and child development. In J. G. Bremner \& T. D. Wachs (Eds.), The Wiley-Blackwell Handbook of Infant Development, Volume 2 (2nd ed.) (pp. 192-220). Hoboken, NJ: Wiley-Blackwell.

Murray, L., Kempton, C., Woolgar, M., \& Hooper, R. (1993). Depressed mothers' speech to their infants and its relation to infant gender and cognitive development. Journal of Child Psychology and Psychiatry, 34(7), 1083-1101.

Murray, L., Marwick, H., \& Arteche, A. (2010). Sadness in mothers' 'baby-talk' predicts affective disorder in adolescent offspring. Infant Behavior and Development, 33(3), 361-364.

Nylen, K. J., Moran, T. E., Franklin, C. L., \& O'Hara, M. W. (2006). Maternal depression: A review of relevant treatment approaches for mothers and infants. Infant Mental Health Journal, 27(4), 327-343.

O'Hara, M.H. (1997) The nature of postpartum depressive disorders. In L. Murray \& P. J. Cooper (Eds.) Postpartum depression and child development (pp. 3-31). New York: Guilford.

O'Hara, M. W., \& Swain, A. M. (1996). Rates and risk of postpartum depression-a meta-analysis. International Review of Psychiatry, 8(1), 37-54.

O'Hara, M. W., Stuart, S., Gorman, L. L., \& Wenzel, A. (2000). Efficacy of interpersonal psychotherapy for postpartum depression. Archives of General Psychiatry, 57(11), 1039-1045.

Richman, N., \& Graham, P. J. (1971). A behavioural Screening questionnaire for use with three-year-old Children. Preliminary findings. Journal of Child Psychology and Psychiatry, 12(1), 5-33.

Seeley, S., Murray, L., \& Cooper, P. J. (1996). The outcome for mothers and babies of health visitor intervention. Health Visitor, 69, 135-138. 
Sinclair, D., \& Murray, L. (1998). Effects of postnatal depression on children's adjustment to school. Teacher's reports. The British Journal of Psychiatry, 172(1), 58-63.

Wickberg, B., \& Hwang, C. P. (1996). Counselling of postnatal depression: a controlled study on a population based Swedish sample. Journal of Affective Disorders, 39(3), 209-216. 
Table 1 - Maternal age, child gender, and Predictive index items, according to group at baseline

\begin{tabular}{|c|c|c|c|c|c|c|}
\hline \multirow{2}{*}{$\begin{array}{l}\text { Measure } \\
\text { Parent and child characteristics }\end{array}$} & \multicolumn{2}{|c|}{$\begin{array}{c}\text { Index(R-HV) } \\
\text { N=82* }\end{array}$} & \multicolumn{2}{|c|}{$\begin{array}{c}\text { Control } \\
\mathrm{N}=\mathbf{8 3}\end{array}$} & \multicolumn{2}{|c|}{$\begin{array}{c}\text { Index(NHS-HV) } \\
\text { N=58* }\end{array}$} \\
\hline & Mean & SD & Mean & SD & Mean & SD \\
\hline \multirow[t]{2}{*}{ Maternal Age (range: 15.60-39.22) } & 27.94 & 5.4 & 28.66 & 6 & 26.04 & 5.82 \\
\hline & $\%$ & $\mathbf{N}$ & $\%$ & $\mathbf{N}$ & $\%$ & $\mathbf{N}$ \\
\hline Child Gender (\% Female) & 42.68 & 35 & 54.22 & 45 & 43.10 & 25 \\
\hline Predictive Index & $\%$ & $\mathbf{N}$ & $\%$ & $\mathbf{N}$ & $\%$ & $\mathbf{N}$ \\
\hline Help conceiving & 18.29 & 15 & 12.05 & 10 & 19.30 & 11 \\
\hline \multicolumn{7}{|l|}{ Pregnancy a positive experience } \\
\hline Yes, definitely & 27.16 & 22 & 25.30 & 21 & 36.21 & 21 \\
\hline Yes, mostly & 66.67 & 54 & 63.86 & 53 & 58.62 & 34 \\
\hline Mostly not \& definitely not & 6.17 & 5 & 10.84 & 9 & 5.17 & 3 \\
\hline Anxiety during pregnancy & 34.15 & 28 & 32.53 & 27 & 39.66 & 23 \\
\hline Depressed over last week & 56.10 & 46 & 54.22 & 45 & 58.62 & 34 \\
\hline Depressed at other times & 65.85 & 54 & 61.45 & 51 & 67.24 & 39 \\
\hline Seek professional help** & 53.70 & 29 & 50.98 & 26 & 43.59 & 17 \\
\hline Seriously interfere with life ${ }^{* *}$ & 59.26 & 32 & 50.98 & 26 & 43.59 & 17 \\
\hline
\end{tabular}

Require medical attention 


$\begin{array}{lcccccc}\text { No } & 61.73 & 50 & 65.06 & 54 & 67.24 & 39 \\ \text { Yes, treated by GP } & 30.86 & 25 & 18.07 & 15 & 17.24 & 10 \\ \text { Hospitalised during pregnancy } & 7.41 & 6 & 16.87 & 14 & 15.52 & 9\end{array}$

Time with current partner

$$
\begin{aligned}
& \text { No partner } \\
& <1 \text { year } \\
& \text { 1-2 years } \\
& \text { 2-5 years } \\
& >5 \text { years }
\end{aligned}
$$

Relationship with current partner ${ }^{\#}$

$$
\text { Close }
$$

Few tensions

Moderate friction

Mother died before age 11

Currently no mother

Close to mother $\$$

No one to confide in ${ }^{+}$

Education

$$
\begin{aligned}
& \text { None/GCSEs } \\
& \text { A Levels/Further Education } \\
& \text { Degree }
\end{aligned}
$$

$\begin{array}{cccccc}4.88 & 4 & 4.82 & 4 & 6.90 & 4 \\ 12.20 & 10 & 15.66 & 13 & 5.17 & 3 \\ 21.95 & 18 & 13.25 & 11 & 22.41 & 13 \\ 24.39 & 20 & 26.51 & 22 & 29.31 & 17 \\ 36.59 & 30 & 39.76 & 33 & 36.21 & 21\end{array}$

$\begin{array}{llllll}56.41 & 44 & 49.37 & 39 & 41.51 & 22\end{array}$

$\begin{array}{llllll}34.62 & 27 & 37.97 & 30 & 52.83 & 28\end{array}$

$\begin{array}{llllll}8.97 & 7 & 12.66 & 10 & 5.66 & 3\end{array}$

$\begin{array}{llllll}3.70 & 3 & 4.82 & 4 & 3.45 & 2\end{array}$

$\begin{array}{llllll}6.10 & 5 & 10.84 & 9 & 5.17 & 3\end{array}$

$\begin{array}{llllll}54.55 & 42 & 66.22 & 49 & 56.36 & 31\end{array}$

$\begin{array}{llllll}18.29 & 15 & 15.66 & 13 & 5.17 & 3\end{array}$

$\begin{array}{llllll}37.80 & 31 & 27.71 & 23 & 62.07 & 36\end{array}$

$\begin{array}{lllllll}40.24 & 33 & 39.76 & 33 & 31.03 & 18\end{array}$

$\begin{array}{llllll}21.95 & 18 & 32.53 & 27 & 6.90 & 4\end{array}$ 
Description of area lived in

$\begin{array}{lllllll}\text { Very satisfactory } & 35.37 & 29 & 36.14 & 30 & 27.59 & 16 \\ \text { Reasonably satisfactory } & 52.44 & 43 & 51.81 & 43 & 53.45 & 31 \\ \text { Unsatisfactory } & 12.20 & 10 & 12.05 & 10 & 18.97 & 11\end{array}$

Attitude to stopping work

$\begin{array}{lcccccc}\text { Not working } & 15.85 & 13 & 13.25 & 11 & 12.07 & 7 \\ \text { Keen to stop } & 23.17 & 19 & 15.66 & 13 & 29.31 & 17 \\ \text { Mixed feelings } & 40.24 & 33 & 49.40 & 41 & 43.10 & 25 \\ \text { Reluctant to stop } & 4.88 & 4 & 6.02 & 5 & 6.90 & 4 \\ \text { Don't intend to stop } & 15.85 & 13 & 15.66 & 13 & 8.62 & 5\end{array}$

\footnotetext{
* Means, standard deviations, and percentages are calculated for valid cases (range: Index $(\mathrm{R}-\mathrm{HV})=81-82$; Index $(\mathrm{R}-\mathrm{HV})=57-58)$;

** of the women who were depressed at other times in their life;

\# of the women who currently have a partner;

$\$$ of the women who currently have a mother;

+ apart from mother or partner.
} 
Table 2 - EPDS scores and Depression Percentages, according to group and child age

\begin{tabular}{|c|c|c|c|c|c|c|c|c|c|c|}
\hline & & \multicolumn{3}{|c|}{ Index(R-HV) } & \multicolumn{3}{|c|}{ Control } & \multicolumn{3}{|c|}{ Index(NHS-HV) } \\
\hline \multirow{5}{*}{ EPDS* } & & $\mathbf{M}$ & SD & $\mathbf{N}$ & $\mathbf{M}$ & SD & $\mathbf{N}$ & $\mathbf{M}$ & SD & $\mathbf{N}$ \\
\hline & 8 Weeks & 7.4 & 4.66 & 82 & 7.6 & 4.77 & 83 & 8.2 & 4.99 & 58 \\
\hline & 18 Weeks & 6.9 & 4.97 & 80 & 6.7 & 4.53 & 79 & 6.1 & 4.81 & 56 \\
\hline & 12 Months & 6.3 & 4.8 & 75 & 6.4 & 4.55 & 76 & 6.9 & 4.62 & 51 \\
\hline & 18 Months & 5.9 & 4.45 & 73 & 6.1 & 4.35 & 74 & 5.8 & 4.27 & 50 \\
\hline \multirow{6}{*}{$\begin{array}{l}\text { SCID } \\
\text { (\% Depressed) }\end{array}$} & & & $\%$ & $\mathbf{N}$ & & $\%$ & $\mathbf{N}$ & & $\%$ & $\mathbf{N}$ \\
\hline & Before 8 Week & & 31.71 & 26 & & 25.30 & 21 & & 36.21 & 21 \\
\hline & 8 Weeks & & 18.29 & 15 & & 14.46 & 12 & & 18.97 & 11 \\
\hline & 18 Weeks & & 20.00 & 16 & & 18.99 & 15 & & 12.50 & 7 \\
\hline & 12 Months & & 13.33 & 10 & & 14.47 & 11 & & 13.73 & 7 \\
\hline & 18 Months & & 6.76 & 5 & & 12.16 & 9 & & 8.00 & 4 \\
\hline
\end{tabular}

* Range: 0-24; the higher the score, the higher the depressive symptomatology 
Table 3 - Maternal Sensitivity and Infant Engagement according to group and child age

\begin{tabular}{lccccccccccc}
\hline & & \multicolumn{1}{c}{ Index(R-HV) } & \multicolumn{3}{c}{ Control } & \multicolumn{4}{c}{ Index(NHS-HV) } \\
\hline & & M & SD & N & M & SD & N & M & SD & N \\
Maternal Sensitivity* & $\mathbf{8}$ Weeks & 3.43 & 0.68 & 80 & 3.40 & 0.71 & 81 & 3.29 & 0.64 & 56 \\
& $\mathbf{1 8 ~ W e e k s ~}$ & 3.33 & 0.62 & 79 & 3.30 & 0.67 & 77 & 3.21 & 0.77 & 55 \\
& $\mathbf{8}$ Weeks & 2.69 & 1.11 & 80 & 2.54 & 1.03 & 81 & 2.83 & 1.15 & 56 \\
Infant Engagement $* *$ & $\mathbf{1 8 ~ W e e k s ~}$ & 2.60 & 0.80 & 79 & 2.70 & 0.81 & 77 & 2.71 & 0.87 & 55
\end{tabular}

* Range: 1.40-5.00; the higher the score, the higher the level of maternal sensitivity.

** Range: 1.00-5.00; the higher the score, the higher the level of infant engagement. 
Table 4 - Behaviour and Relationship Problems, and BSQ Scores, according to group and child age

\begin{tabular}{|c|c|c|c|c|c|c|c|c|c|c|}
\hline & & \multicolumn{3}{|c|}{ Index(R-HV) } & \multicolumn{3}{|c|}{ Control } & \multicolumn{3}{|c|}{ Index(NHS-HV) } \\
\hline & & & $\%$ & $\mathbf{N}$ & & $\%$ & $\mathbf{N}$ & & $\%$ & $\mathbf{N}$ \\
\hline Behaviour & 8 Weeks & & 56.25 & 45 & & 48.75 & 39 & & 29.09 & 16 \\
\hline \multirow[t]{2}{*}{ Problems } & 18 Weeks & & 35.44 & 28 & & 40.26 & 31 & & 25.45 & 14 \\
\hline & 12 Months & & 32.86 & 23 & & 45.07 & 32 & & 23.53 & 12 \\
\hline Relationship & 8 Weeks & & 32.35 & 22 & & 42.67 & 32 & & 33.33 & 16 \\
\hline \multirow[t]{3}{*}{ Problems } & 18 Weeks & & 32.43 & 24 & & 44.00 & 33 & & 30.19 & 16 \\
\hline & 12 Months & & 28.57 & 20 & & 30.88 & 21 & & 22.92 & 10 \\
\hline & & $\mathbf{M}$ & SD & $\mathbf{N}$ & $\mathbf{M}$ & SD & $\mathbf{N}$ & $\mathbf{M}$ & SD & $\mathbf{N}$ \\
\hline BSQ & 18 Months & 3.83 & 3.08 & 52 & 3.90 & 3.26 & 59 & 3.59 & 2.78 & 39 \\
\hline
\end{tabular}

* Range: 0.00-14.00; the higher the score, the greater the presence of behavioural problems. 
Table 5 - Perceptions of the Intervention questionnaire scores according to group

\begin{tabular}{lccccccccc}
\hline \multicolumn{1}{c}{ Intervention Questions* } & \multicolumn{2}{c}{ Index(R-HV) } & \multicolumn{3}{c}{ Control } & \multicolumn{3}{c}{ Index(NHS-HV) } \\
\hline & M & SD & N & M & SD & N & M & SD & N \\
My health advisor understood how I felt & 2.62 & 0.54 & 81 & 1.86 & 0.72 & 83 & 2.53 & 0.68 & 57 \\
My health advisor gave me good advice about infant care & 2.77 & 0.48 & 79 & 1.95 & 0.94 & 83 & 2.41 & 0.85 & 56 \\
My health advisor helped me sort out practical problems with the baby & 2.51 & 0.59 & 81 & 1.66 & 1.06 & 83 & 2.36 & 0.92 & 56 \\
My health advisor made me appreciate things about my baby's abilities & 2.80 & 0.49 & 81 & 1.06 & 1.02 & 82 & 2.52 & 0.79 & 56 \\
My health advisor helped me communicate with my baby & 2.47 & 0.73 & 81 & 0.62 & 0.80 & 81 & 2.05 & 1.02 & 56 \\
My health advisor's visits were really helpful & 2.77 & 0.51 & 81 & 1.83 & 1.01 & 83 & 2.54 & 0.76 & 56 \\
\hline *
\end{tabular}

* Range for all questions: 0.00-3.00; the higher the score, the higher the perception of support. 
Figure 1 - CONSORT Diagram

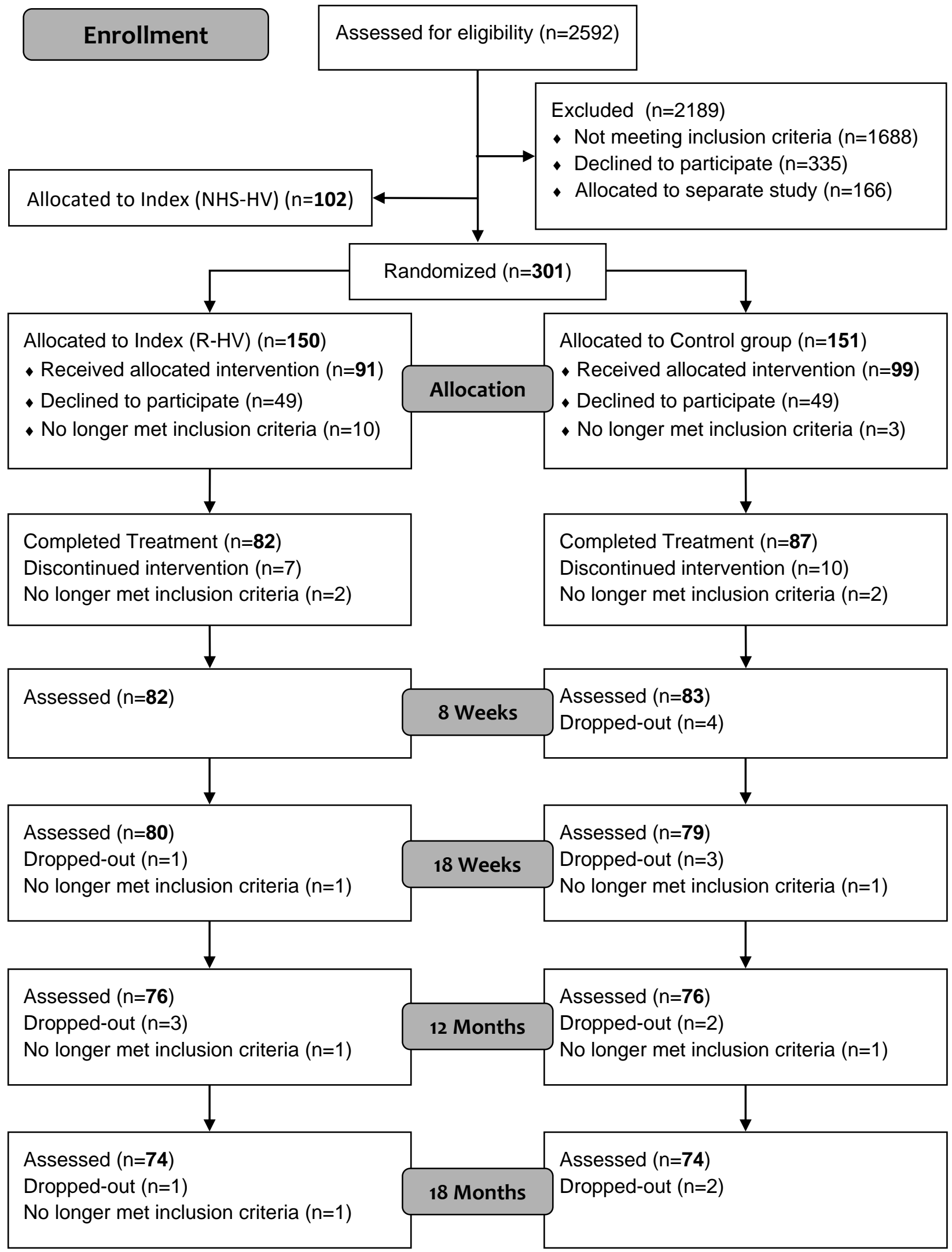

